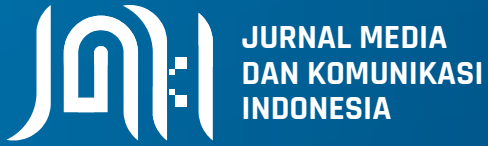

92 Strategi Penyusunan Pesan Informatif - Persuasif Dalam Data Covid-19 Oleh Humas Diskominfo Kota Bogor di Media Sosial

Shafa Tsamara Nugraini, Abdul Kholik

104 Strategi Redaksi Catch Me Up! Dalam Menghadapi Persaingan Industri Media Online

Aaron Reghanada Prasetyawibowo, Ni Made Ras Amanda Gelgel, I Gusti Agung Alit Suryawati

115 Permainan Simulasi Kencan sebagai Medium Romantic Loneliness

131 Pengaruh Kredibilitas, Kualitas Pendekatan Emosional, Dan Kualitas Isi Pesan Terhadap Efektivitas Kampanye "Love Myself" Antonia Meme 148 Informasi Kinerja Pemerintah Daerah di Media Online 


\section{Jurnal Media dan Komunikasi Indonesia}

Jurnal Media dan Komunikasi (JMKI) diterbitkan Departemen Ilmu Komunikasi, Fakultas IImu Sosial dan IImu Politik, Universitas Gadjah Mada. Terbit dua kali setahun, Maret dan September. JMKI dedikasikan untuk mempublikasikan dan mendiseminasikan penelitian, kajian, dan fenomena dalam IImu Komunikasi khususnya di Indonesia. Ruang lingkup manuskrip yang diterbitkan di JMKI adalah manifestasi dari visi Departemen Ilmu Komunikasi yaitu "Crafting Well Informed Society." JMKI mengundang para peneliti maupun praktisi dari berbagai disiplin keilmuan untuk menulis tentang kajian media dan komunikasi seperti jurnalisme dan media, media entertainment, periklanan, humas, cultural studies, film studies, dan game studies.

\section{Editor in Chief}

Rajiyem, Faculty of Social and Political Sciences Universitas Gadjah Mada

\section{Deputy Editor in Chief}

I Gusti Ngurah Putra, Faculty of Social and Political Sciences Universitas Gadjah Mada

\section{Editorial Board}

Wisnu Prasetya Utomo, Faculty of Social and Political Sciences Universitas Gadjah Mada

Widodo Agus Setianto, Faculty of Social and Political Sciences Universitas Gadjah Mada

\section{Reviewer}

Muninggar Saraswati, Swiss German University

Gregoria Arum Yudarwati, Universitas Atma Jaya

Rajab Ritonga, Faculty of Communication Science, Universitas Prof. Dr. Moestopo (Beragama)

Effendi Gazali, Universitas Prof. Dr. Moestopo (Beragama)

Megandaru Widhi Kawuryan, Departement of Government, Institut Pemerintahan Dalam Negeri (IPDN)

Hermin Indah Wahyuni, Faculty of Social and Political Sciences, Universitas Gadjah Mada

Novi Kurnia, Faculty of Social and Political Sciences, Universitas Gadjah Mada

Nunung Prajarto, Faculty of Social and Political Sciences, Universitas Gadjah Mada

\section{Editorial Secretary}

Jusuf Ariz Wahyuono, Faculty of Social and Political Sciences Universitas Gadjah Mada

\section{Mailing Address}

Departemen Ilmu Komunikasi

Jalan Sosio Yustisia No. 2 Bulaksumur

Yogyakarta 55281

Email:jmki@ugm.ac.id 


\section{Daftar ISI}

Strategi Penyusunan Pesan Informatif - Persuasif Dalam Data Covid-19 Oleh Humas Diskominfo Kota Bogor di Media Sosial

Shafa Tsamara Nugraini, Abdul Kholik

Strategi Redaksi Catch Me Up! Dalam Menghadapi Persaingan Industri Media Online

Aaron Reghanada Prasetyawibowo, Ni Made Ras Amanda Gelgel, I Gusti Agung Alit Suryawati

Permainan Simulasi Kencan sebagai Medium Romantic Loneliness

Sarah Noverianti, Ardian Indro Yuwono

Pengaruh Kredibilitas, Kualitas Pendekatan Emosional, Dan Kualitas Isi Pesan Terhadap Efektivitas Kampanye "Love Myself"

Antonia Meme

Informasi Kinerja Pemerintah Daerah di Media Online

Nur Imroatus Sholikhah 


\title{
Strategi Redaksi Catch Me Up! Dalam Menghadapi Persaingan Industri Media Online
}

\author{
Aaron Reghanada Prasetyawibowo \\ | Mahasiswa Program Studi Ilmu Komunikasi, Universitas Udayana \\ Bisa dihubungi melalui email reghanada@yahoo.com \\ Ni Made Ras Amanda Gelgel \\ | Staff Pengajar Program Studi Ilmu Komunikasi, Universitas Udayana \\ Bisa dihubungi melalui email reghanada@yahoo.com \\ I Gusti Agung Alit Suryawati \\ | Staff Pengajar Program Studi Ilmu Komunikasi, Universitas Udayana \\ Bisa dihubungi melalui email reghanada@yahoo.com
}

\begin{abstract}
ABSTRAK
Catch Me Up! is a pioneering online media that has innovation through daily newsletters. In addition, the language features brought by Catch Me Up! using everyday Indonesian which is used by many millennial generations. This study aims to determine how the implementation of the Catch Me Up! in the face of competition in the online media industry. This research is reviewed based on the application of media management and editorial strategies used using four management functions of George $R$ Terry with implementation of actuating process from Tommy Suprapto. To describe it, this research uses descriptive qualitative research methods. Primary data was obtained based on the results of in-depth interviews with 2 key-informants, while secondary data was obtained from the study of literature. The results of this study show the editorial strategy of Catch Me Up! included in the implementation stage. Analysis of the functions of planning, organizing, actuating and controlling shows Catch Me Up! has an editorial strategy in facing the online media industry competition, namely by making a daily newsletter using slank words that is easily understood by the public. Everything is done through editorial management so that the quality of the content produced is in accordance with the standards.
\end{abstract}

Keywords: Strategy, Editorial, Media Management, Catch Me Up!, Online Media

\section{Pendahuluan}

Persaingan pada industri media seringkali digambarkan sebagai sebuah segitiga, yaitu persaingan dari sisi pembaca, pemasang iklan, dan pandangan masyarakat. Subagio $M$ Warnosumarto (2020) mengatakan, pembaca bukanlah pelanggan dari sebuah media, namun kepercayaan dari pembaca ini yang kemudian dijadikan acuan kepada pemasang iklan sebagai pelanggan. Persaingan industri ini tidak terlepas dari adanya kebebasan pers setelah zaman orde baru. UU Pers No.40/1999 Bab IV Pasal 9 poin 1 mengatakan "Setiap warga negara Indonesia dan negara berhak mendirikan perusahaan pers". Menurut KBBI, Pers merupakan sebuah lembaga yang menjadi sarana produk jurnalistik untuk bisa disampaikan kepada khalayak atau dalam kata lain perusahaan media. Kebebasan pers seakan menjadi kran pembuka bagi persaingan industri yang lebih ketat dimana setiap orang berhak mengunggah informasi kepada khalayak umum. 
Pers juga semakin dimudahkan dengan masuknya era internet yang membuat perusahaan media dapat dengan mudah membuat media berbasis online atau yang lebih dikenal dengan media online.

Menurut Ashadi Siregar (2006), media online merupakan sebutan umum untuk sebuah media yang berbasis telekomunikasi dan multimedia (komputer dan internet). Masyarakat saat ini cenderung menyukai produk sajian dalam bentuk digital seperti e-books, e-magazine, online magazine, e-news dan lain sebagainya. Hal ini dibuktikan melalui lembaga riset Gesellschaft für Konsumforschung dan Indonesian Digital Association (IDA) yang dimuat pada laman Okezone.com bahwa masyarakat yang tinggal di daerah perkotaan di Indonesia mulai beralih mengkonsumsi berita digital. Informasi dalam bentuk media visual seperti ini lebih mudah untuk diakses sehingga masyarakat di seluruh dunia yang terhubung dengan jaringan internet dapat menerima informasi tersebut (Okezone.com, 2016).

Gaya hidup masyarakat menuntut adanya perkembangan mengikuti sesuatu yang baru. Dahulu masyarakat menkonsumsi berita dengan membaca koran dengan lembaran yang besar. Namun dengan berkembangnya teknologi, membuat masyarakat beralih dengan menkonsumsi berita melalui media online yang hanya dengan genggaman smartphone dapat menikmati berita (Pramesti dkk, 2019).

Yosep Adi Prasetyo selaku ketua Dewan Pers tahun 2016-2019, memperkirakan bahwa pada tahun 2018, terdapat 43.000 media online, namun hanya 629 media online yang berbadan hukum
(Prasetyo, 2018).

Riset dari Roy Morgan menunjukan bahwa sejak April 2017-Maret 2018, terdapat 10 media online yang paling sering dikunjungi oleh masyarakat Indonesia. Hasil riset tersebut juga menunjukan bahwa Detik.com merupakan pemimpin media online di Indonesia dengan jumlah pengakses 8,7 Juta dalam periode ratarata empat minggu (Roy Morgan, 2018).

Gambar 1. Grafik 10 media online terbesar di Indonesia

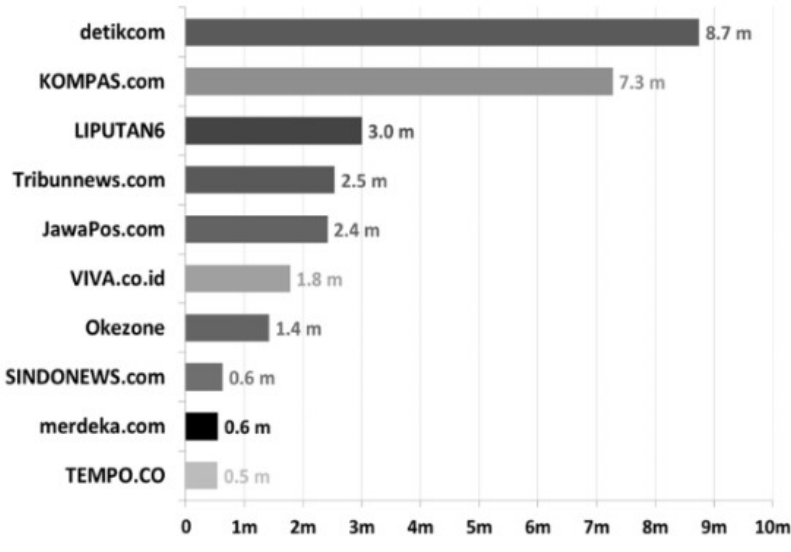

Sumber: www.roymorgan.com

Faktor yang menyebabkan detik.com bisa meraih peringkat teratas salah satunya detik.com selalu memberikan berita-berita breaking news dan terdahulu. Hal itu bisa terealisasi karena didukung dengan banyaknya reporter yang tersebar di seluruh daerah untuk selalu memberikan informasi terbaru (Benazir, 2015). Cara ini menjadi salah satu strategi yang digunakan oleh detik.com untuk terus bisa bersaing dengan kompetitornya.

Strategi yang menarik dan inovatif harus diciptakan oleh redaksi agar mendapat perhatian khusus masyarakat. Proses ini akan menyangkut 
informasi atau berita mana yang layak muat atau pun tidak, layak atau tidaknya sebuah informasi atau berita akan dikembalikan kepada seseorang yang mengambil keputusan yaitu pemimpin redaksi (Patia dan Rajaguguk, 2020).

Adek Ferizal dkk (2017) mengatakan bahwa dalam beberapa tahun terakhir, banyak redaksi pada media online menunjukan kemasan dan tema-tema inovatif dalam menyampaikan sebuah informasi. Pemanfaatan kembali mailing list (milis) sebagai sebuah media penyebaran informasi memberikan angin segar dalam persaingan industri media online saat ini. Mailing list (milis) merupakan teknologi yang sudah lama ditemukan, namun jarang dipakai saat ini karena banyaknya teknologi yang makin berkembang.

Menurut E. Krol, seperti dikutip Istyas Fadillah (2010), mailing list adalah suatu cara bagi para pengguna untuk tetap up to date dalam berita-berita terkini di jaringan internet melalui pengiriman surat elektronik (e-mail). Sebuah perusahaan berita berlangganan Catch Me Up! hadir dengan tujuan untuk membuat pembaca bisa mendapatkan informasi update, setiap pagi melalui kotak masuk e-mail menggunakan teknologi mailing list.

Catch Me Up! Berbeda dengan media online lainnya. Catch Me Up! memberikan newsletter melalui e-mail pembacanya setiap pukul 6 pagi secara gratis sebagai sajian utama. Hal ini sesuai dengan tujuan dari Catch Me Up! yakni melayani kebutuhan kaum milennial yang punya banyak hal yang harus dilakukan, tapi hanya mempunyai waktu yang singkat untuk membaca berita. Catch Me Up! hadir untuk membantu para milennial ini untuk mengetahui apa yang sedang terjadi di sekelilingnya dengan lebih mudah. (Catch Me Up!, 2019). Mereka juga memberikan udara segar bagi industri media dengan gaya penyampaian beritanya yang lebih kekinian, membuat para pembaca milenial lebih mudah untuk memahami konteks isi berita dan membuat isi berita menjadi ringan untuk dibaca walaupun topik yang diangkat berat (Ellyta Rahma, 2020).

Berdasarkan penjelasan diatas dapat, ditarik kesimpulan tujuan dari penelitian ini untuk mengetahui strategi redaksi Catch Me Up! dalam menghadapi persaingan industri media online.

\section{Tinjauan Pustaka}

\section{Manajemen Media Massa Online}

Pengertian manajemen menurut Aldag dan Stearns seperti dikutip wibowo (2017), merupakan suatu proses perencanaan pengorganisasian dan pengelolaan staf, kepemimpinan dan pengawasan dalam organisasi yang dilakukan secara sistematis guna mencapai tujuan tertentu. Sedangkan media massa diartikan sebagai suatu alat penghantarpesan yang dikirimkan dari sumber hingga sampai kepada khalayak dengan berbagai peralatannya (Cangara, 2008).

Berdasarkan pengertian tersebut, dapat disimpukan bahwa manajemen media massa merupakan pengelolaan atau Suatu proses merencanakan, mengorganisir dan mengarahkan suatu perusahaan media dalam menyajikan informasiatau berita kepada khalayak.

Dalam suatu perusahaan media massa online, terdapat manajemen media massa online. GeorgeR Terry seperti dikutip Yusuf Zaenal Abidin 
(2015) menyebut ada empat fungsi dasar dalam manajemen supaya tujuan organisasi tersebut bisa tercapai. Fungsi dasar tersebut antara lain perencanaan (planning), pengorganisasian (organizing), pelaksanaan (actuating) dan pengawasan (controlling), yang lebih dikenal POAC.

\section{Perencanaan}

Fungsi perencanaan merupakan fungsi yang terkait dengan pemilihan tujuan pembuatan kebijakan dan strategi yang ada supaya mencapai tujuan yang dikehendaki. Perencanaan dapat dilihat sebagai proses suatu kerangka untuk mengambil keputusan dan penyusunan kebijakan selanjutnya di masa depan.

\section{Pengorganisasian}

Pengorganisasiaan mempunyai tujuan untuk penentuan dan pengelompokan berbagai unsur baik itu kegiatan atau manusia (pelaku kegiatan) agar pelaksanaan dari kegiatan bisa sejlan dengan apa yang ditetapkan saat tahap perencanaan.

\section{Pelaksanaan}

Pelaksanaan merupakan proses penerapan dari perencanaan yang sudah dibuat sebelumnya. Menurut Tommy Suprapto, seperti dikutip Yusuf (2015:154) actuating merupakan implementasi dari suatu kegiatan sesuai dengan perencanaan.

\section{Pengawasan atau Evaluasi}

Fungsi pengawasan atau pengendalian ini merupakan upaya yang sistematis untuk menetapkan sebuah standar penilaian serta evaluasi supaya memastikan bahwa hasil kegiatan sesuai dengan apa yang telah direncanakan. Tommy Supraprto, seperti dikutip Yusuf Zaenal Abidin (2015) menjelaskan bahwa hasil riset liputan sebaiknya dievaluasi dahulu sebelum disebarkan kepada publik.

\section{Strategi Redaksi Media Online}

Media online perlu mempunyai strategi untuk menarik khalayak. Hal ini dilakukan untuk menghindari pengambilan keputusan berita atau informasi yang asal karena strategi yang kurang tepat dilakukan dan Kebijakan redaksi yang sudah melenceng dengan mengabaikan kualitas isi suatu berita atau informasi. Sedangkan infromasi atau berita merupakan unsur erpenting dalam aktivitas sebuah media atau pers, padahal tidak ada berita tanpa aktivitas jurnalistik (Prasetyo, 2018).

Senja Nilasari (2014:3) menyebutkan, strategi merupakan suatu cara atau taktik yang digunakan untuk menunjukkan keunggulan dan kekuatan perusahaan atau organisasi dalam mencapai suatu tujuan. Terjadinya kecepatan inovasi pasar yang baru dan perubahan pola konsumen memerlukan kompetensi inti (core competence).

Redaksi merupakan bagian atau sekumpulan orang dalam sebuah organisasi perusahaan media (cetak, elektronik, dan online) yang bertugas untuk menolak atau mengizinkan pemuatan sebuah tulisan atau berita melalui berbagai pertimbangan di antaranya ialah bentuk tulisan berupa berita, bahasa, akurasi, dan kebeneran tulisan (Manulang, 1996:16).

Sebuah media pers pada dasarnya digerakan oleh komponen keredaksian yang dipimpin oleh seorang pemimpin redaksi 
(pemred). Perkembangan suatu media pers tidak dapat dilepaskan dari tangan seorang pemred. Seorang pemred harus mempunyai visi untuk menjalankan medianya supaya tau kemana akan arah tujuan medianya (Ashadi Siregar, 2006:204).

\section{Ekonomi Media Online}

Media massa menjual produknya dengan dua cara Mereka memeroleh pendapatan dengan menjual produk langsung kepada khalayak, atau mereka meraih pendapatan dari pengiklan yang memasang iklan untuk khalayak yang disediakan oleh media.

Al-Din dan Wibawa (2021) mengatakan, perkembangan media massa menjadi sebuah institusi ekonomi, melahirkan disiplin ilmu yang biasa disebut ekonomi media (media economics). Ekonomi media memandang media sebagai industri atau institusi ekonomi yang berupaya mencari keuntungan.

Picard seperti dikutip Usman KS (2009:3) menjelaskan bahwa ekonomi media berkaitan dengan bagaimana industri media mengalokasikan berbagai sumber untuk menghasilkan materi informasi dan hiburan untuk memenuhi kebutuhan audiens, pengiklan dan institusi lainnya.

\section{Metode}

Penelitian ini menggunakan jenis penelitian deskriptif kualitatif. Pendekatan kualitatif akan menjelaskan sebuah fenomena sampai sedalam-dalamnya karena dalam riset ini, kualitas data lebih ditekankan daripada kuantitas data (Rachmat, 2006:56). Penelitian ini menggunakan jenis penelitian kualitatif karena dapat membahas penjelasan mengenai strategi redaksi Catch Me Up! lebih dalam.

Data primer, adalah data yang diperoleh secara langsung dari obyek yang diteliti. Data primer dalam penelitian ini berupa hasil wawancara mendalam dari key informan. Data sekunder, merupakan data yang diperoleh secara tidak langsung dapat mendukung data primer berupa dokumen terkait. Dalam penelitian ini, yang menjadi informan kunci merupakan orangorang yang mempunyai jabatan dan peranan penting dalam internal Catch Me Up!. Informan yang dipilih yaitu Haifa Inayah selaku CEO Catch Me Up! dan Kania Mezania selaku Head of content.

Dalam penelitian ini, peneliti menggunakan dua teknik pengumpulan data, yaitu wawancara mendalam dengan berdialog langsung bersama informan yang telah ditentukan untuk mendapatkan informasi mengenai strategi redaksi Catch Me Up! dan dokumentasi yang merupakan pencarian data melalui pencatatanpencatatan dari dokumen yang terdapat pada lokasi penelitian Catch Me Up!

Untuk memeriksa validitas data, peneliti menggunakan teknik triangulasi sumber sebagai teknik verifikasi terhadap hasil temuan yang sudah didapatkan. Triangulasi sumber dimaksudkan untuk mendapatkan data dari sumber yang berbeda dengan teknik yang sama.

\section{Hasil dan Pembahasan}

\section{Perencanaan Konten}


Dalam menentukan target pembaca Catch Me Up!, Haifa menuturkan bahwa e-mail dirasa lebih mudah untuk mendapatkan audience bagi Catch Me Up! karena belum banyak media yang menyentuh pasar di platform e-mail. Selain itu, Catch Me Up! juga mempunyai target khusus untuk pembaca. Target khusus yang dimaksud adalah perempuan. Dengan latar belakang banyak sekali media di Indonesia yang sering mengobjektifikasi perempuan dalam muatan berita, Catch Me Up! hadir sebagai media yang ramah bagi perempuan.

Dalam alur kerja tim Catch Me Up! untuk membuat sebuah newsletter, diskusi harian merupakan agenda pertama dalam membuat sebuah newsletter. Selain itu, komunikasi yang dilakukan antara anggota dominan menggunakan grup whatsapp. Untuk diskusi bersama anggota dilakukan setiap hari melalui grup whatsapp dengan percakapan melalui teks, namun tidak ada rapat harian khusus dengan percakapan verbal dikarenakan sulitnya mencari waktu luang bersama.

Komunikasi yang dilakukan untuk melakukan diskusi dilakukan secara online menggunakan grup whatsapp. Selain itu, jam kerja bagi para anggota tim berbeda-beda, tergantung kesibukan mereka dan kapan mereka dibutuhkan. Dalam wawancara ini terlihat Peranan CEO sangat penting karena ia yang akan mengorganisir pekerjaan setiap anggotanya dan juga menentukan isu apa yang akan diangkat.

\section{Pengorganisasian Redaksi}

Dalam bagian pengorganisasian redaksi,
CEO mempunyai peran dan tanggung jawab mulai dari mengorganisir anggota tim sampai dengan menentukan isu. Untuk menentukan berita apa yang akan diangkat oleh Catch Me Up!, sepenuhnya masih menjadi tanggung jawab CEO dalam memutuskan dan mengkoordinasikan kepada tim apa saja yang harus dicari dan dikerjakan. Sementara itu, anggota tim yang lain hanya mengusulkan saja terhadap isu-isu yang akan diangkat.

\section{Proses Pembuatan Newsletter}

Bagian pelaksanaan newsletter merupakan bagian terpenting dalam alur kerja redaksi Catch Me Up!. Dalam bagian pelaksanaan, CEO melakukan riset dengan tim nya yang berjumlah enam orang setiap hari untuk mempersiapkan newsletter. Pada pelaksanaanya, CEO dan tim menggunakan banyak referensi dari media yang sudah besar dan terpercaya untuk membuat sebuah berita. Riset dari berbagai sumber dilakukannya guna meminimalisir terjadinya disinformasi. Sebagai media online yang baru berkembang, Catch Me Up! belum mempunyai wartawan lapangan yang bisa mencarikan data primer bagi kebutuhan redaksi Catch Me Up!.

Untuk menghadapi persaingan industri media online, CEO mempunyai sebuah strategi yang akan terus digunakan dan menjadi ciri khas dari Catch Me Up! sendiri. Penggunaan bahasa sehari-hari yang sederhana akan terus digunakan dalam newsletter dan konten pada platform yang digunakan oleh Catch Me Up!. Hal ini menjadi nilai jual tersendiri bagi Catch Me Up!. 
Perbedaan yang dimiliki Catch Me Up! dari media online lain untuk bisa bersaing dan bertahan dalam industri media online. Perbedaan ini yang membuat Catch Me Up! bisa terus bertahan dalam industri media online. Namun dibalik perbedaan tersebut, Haifa masih menggunakan rumusan yang umum digunakan oleh banyak media dalam membuat sebuah berita. Rumusan yang digunakan untuk membuat sebuah berita ialah $5 \mathrm{~W}+1 \mathrm{H}$. Perbedaan terlihat pada tulisan yang dibuat, jika media lain menggunakan tulisan deskriptif, Catch Me Up! menggunakan metode penulisan tanya jawab untuk membuat pembacanya tidak bosan membaca sebuah berita.

\section{Verifikasi dan Evaluasi}

Redaksi Catch Me Up! melakukan verifikasi terhadap berita yang akan dibagikan dan melakukan evaluasi terhadap newsletter yang telah mereka bagikan. Verifikasi dilakukan oleh CEO sebagai orang yang mempunyai wewenang untuk memutuskan kesiapan sebuah berita untuk dibagikan. Sedangkan evaluasi open rate newsletter dan media sosial, dilakukan oleh Sosial Media Officer yang nantinya juga dilaporkan kepada CEO.

Evaluasi dilakukan salah satunya guna melawan sentimen negatif pembaca terhadap newsletter Catch Me Up!. Hal ini masih harus terus dilakukan terus dilakukan, pasalnya newsletter merupakan sebuah inovasi baru dalam dunia pers Indonesia, masih ada yang menganggap bahwa newsletter merupakan kegiatan spamming. Untuk mencegah para pembaca melakukan tindakan unsubscribe, Catch Me Up! hanya hadir mengirimkan newsletter satu kali setiap harinya pada hari senin sampai dengan jumat, selain itu peningkatan kualitas pembuatan konten yang bagus dan juga menarik juga terus dilakukan guna menjaga kesetiaan para pembaca.

Evaluasi dilakukan juga untuk melihat presentase pembaca rutin dilakukan oleh Catch Me Up! setiap bulan. Evaluasi open rate seperti ini penting dilakukan untuk melihat target audience yang telah diperoleh setiap bulannya. Selain itu, mengevaluasi open rate seperti ini bisa menjadi patokan harga beriklan di Catch Me Up!.

\section{Analisis POAC}

Hasil temuan akan dipaparkan berdasakan fungsi dasar manajemen POAC yang dikembangkan oleh George R. Terry dan penerapan fungsi actuating dari Tommy Suprapto yang terdiri dari Planning Organizing, Actuating, Controlling yaitu perencanaan, pengorganisasian, pelaksanaan, evaluasi atau pengawasan untuk menganalisa strategi redaksi Catch Me Up!.

Terdapat kecenderungan strategi redaksi yang diterapkan oleh Catch Me Up! terdapat dalam fungsi pelaksanaan. Akan tetapi, strategi redaksi tersebut tidak dapat berjalan jika tidak didukung fungsi manajemen lainnya.

\section{Planning (Perencanaan)}

Tahapan awal perencanaan redaksi Catch Me Up! adalah melaksanakan diskusi harian melalui grup whatsapp. Diskusi ini dipimpin oleh CEO dan bersifat terbuka untuk siapa saja anggota tim yang ingin memberikan masukan isu ataupun 
ingin berkomentar terhadap sebuah isu. Adapun kriteria isu tersebut diperkirakan bisa berpengaruh kepada pembaca dan juga dirasakan oleh masyarakat.

Diskusi ini dilakukan setiap hari di pagi hari sampai dengan siang hari. Adanya diskusi ini dikarenakan banyaknya anggota tim Catch Me Up! yang mempunyai kesibukan lainnya. Dengan lamanya waktu diskusi, anggota tim bisa lebih leluasa, tidak keterbatasan waktu untuk memberikan usulannya kedalam forum.

Saat siang hari sekitar 15:00 WIB, CEO sudah bisa memutuskan isu apa yang akan diangkat untuk keesokan harinya dan mengumumkan di grup whatsapp. Setelah diumumkan di grup whatsapp, langkah selanjutnya adalah CEO memberikan tugas kepada head of content untuk mencarikan datadata yang diperlukan dan melakukan riset guna dijadikan draf pertama agar di malam hari antara pukul 19:00-20:00 WIB sudah bisa diberikan kepada CEO.

\section{Organizing (Pengorganisasian)}

Pada tahap pengorganisasian, CEO memegang peranan yang penting. Seorang CEO bertugas membagikan tugas tanggung jawab apa saja yang harus dilakukan oleh head of content, editor, dan juga desainer grafis. Pengorganisasian yang dilakukan dengan cara memberikan tugas apa saja yang harus dikerjakan, siapa yang mengerjakan, bagaimana tugas-tugas tersebut dikelompokkan, dalam media online Catch Me Up!

Seorang CEO di Catch Me Up! juga mempunyai tugas untuk mengkoordinir seluruh kegiatan keredaksian. Hal ini dikarenakan Catch
Me Up! merupakan perusahaan media yang tergolong baru merintis dan masih tergolong kecil. Lebih lanjut mengenai koordinasi redaksi, CEO memberikan tugas kepada head of content untuk mencarikan sumber-sumber, mengumpulkan data-data $5 \mathrm{~W}+1 \mathrm{H}$ dari sebuah isu berita. Kemudian, head of content bertugas untuk mencarikan data tersebut dan merangkumnya menjadi sebuah tulisan draf pertama newsletter. Selanjutnya head of content memberikan draf pertama newsletter kepada CEO.

Sebagai perusahaan media yang masih merintis, Catch Me Up! belum mempunyai banyak penulis yang khusus untuk menulis setiap rubrik, hal ini menyebabkan segala jenis rubrik dapat ditulis oleh head of content dan juga CEO. Mereka saling melengkapi untuk membuat sebuah tulisan berita newsletter Catch Me Up!.

\section{Actuating (Pelaksanaan)}

Tahapan pelaksanaan merupakan tahapan yang paling penting dalam alur pembuatan berita di Catch Me Up!. Tahapan pelaksanaan merupakan tahap merealisasikan rencana menjadi sebuah kenyataan melalui berbagai pengarahan. Dalam tahap pelaksanaan pembuatan konten, semua anggota tim akan melaksanakan tugas dan tanggung jawabnya masing-masing. Selain itu, pelaksanaan dalam sebuah alur kerja manajemen redaksi merupakan tahapan yang sangat penting, karena dengan adanya pelaksanaan atau tindakan, pembuatan sebuah newsletter di Catch Me Up! bisa terealisasi. Setiap anggota yang melaksanakan pekerjaan ini, sebelumnya juga telah diberikan arahan oleh CEO. Apabila ada kendala dan 
pertanyaan, anggota bisa langsung memberitahukannya lewat grup whatsapp ataupun pesan pribadi. Berikut proses penyajian konten berita dari Catch Me Up! :

1). Pencarian informasi isu terkini yang bisa dijadikan berita. Kumpulan isu ini didapatkan oleh CEO, head of content, ataupun anggota lainnya. Argumen dari setiap anggota dibutuhkan, untuk melihat suatu isu dari berbagai pandangan. Diskusi anggota dilakukan melalui grup whatsapp.

2). Penentuan isu berita yang akan diangkat kedalam newsletter keesokan harinya. Hal ini dilakukan oleh CEO sebagai penentu isu apa saja yang akan diangkat. Tolak ukur yang digunakan CEO untuk memilih sebuah isu berita adalah aktualitas, relevansi dengan pembaca, pentingnya isu.

3). Riset dari isu berita yang akan diangkat dengan tahapan verifikasi dari berbagai sumber terpercaya baik media nasional maupun internasional. Merangkai sebuah informasi menjadi menarik, singkat dan mudah dimengerti oleh pembaca. Berita tersebut harus mengandung unsur $5 \mathrm{~W}+1 \mathrm{H}$, berita yang ditulis harus melihat dari berbagai pandangan, dan juga gaya bahasa sehari-hari yang bisa mudah dimengerti banyak pembaca. Newsletter juga merupakan salah satu nilai lebih yang dimiliki Catch Me Up!. Nilai lebih tersebut yang membuat Catch Me Up! bisa bersaing di industri media online sampai sekarang.

4). Proof reading perlu dilakukan untuk memverifikasi data-data yang sudah dirangkum supaya tidak terjadi disinformasi. Selain itu, proof reading juga dilakukan guna menyelaraskan gaya bahasa yang digunakan oleh Catch Me Up! supaya bisa mudah dimengerti oleh para pembaca.

5). Setelah dilakukan proof reading oleh CEO, berita tersebut akan dikirimkan kepada editor untuk memastikan bahasa yang digunakan benar secara gramatikal. Jika secara gramatikal dan tata bahasa sudah benar, barulah editor akan melakukan penjadwalan untuk terbit pada jam enam pagi.

\section{Controlling (Evaluasi atau pengawasan)}

Evaluasi atau pengawasan oleh Catch Me Up!, lebih menekankan untuk selalu melakukan riset yang mendalam dan juga detail dalam melakukan proof reading. Hal tersebut dilakukan mengingat untuk meminimalisir terjadinya disinformasi dalam newsletter.

Evaluasi tidak dilakukan secara berkala setiap harinya, namun social media officer akan melakukan evaluasi berkala setiap bulan untuk mengumpulkan data informasi open rate dari newsletter dan seluruh sosial media. Evaluasi ini akan memperlihatkan peningkatan atau penurunan pembaca yang diperoleh setiap bulannya.

Media online mempunyai kelebihannya yaitu dapat dibaca berulang kali kapanpun dan dimanapun menggunakan gawai atau komputer dengan akses internet. Hal tersebut membuat anggota Catch Me Up! bisa melakukan pengamatan terhadap ada atau tidaknya kesalahan penulisan ataupun umpan balik yang 
diberikan oleh pembaca. Sebelum pembaca sadar dengan satu kesalahan dalam tulisan Catch Me Up!, anggota tim bisa lebih dahulu mengambil tindakan sedini mungkin dan bisa langsung melaporkannya kepada grup whatsapp atau melalui pesan pribadi kepada CEO.

\section{Kesimpulan}

Strategi yang telah digunakan tercipta karena adanya kesadaran CEO bahwa media online di Indonesia membutuhkan inovasi baru. Berdasarkan hasil temuan dan analisis penelitian, strategi redaksi yang digunakan oleh Catch Me Up! salah satunya yaitu Penggunaan bahasa seharihari supaya bisa mudah dipahami oleh pembaca, mengirimkan newsletter di pagi hari, prinsip jurnalistik (pentingnya penerapan cover both side), riset yang mendalam dengan berbagai referensi perlu dilakukan untuk meminimalisir disinformasi, media yang ramah perempuan dan iklan bukan target utama.

Disamping itu, strategi redaksi Catch Me Up! dalam penyajian berita diimplementasikan melalui teks beritanya yang berbentuk tanya jawab, dan memaksimalkan saluran-saluran media sosial untuk bisa menjangkau para pembaca baru. Konten yang disajikan bisa membuat pembaca nyaman karena penyajian berita yang santai, ringkas, seperti membaca penjelasan dari teman. Gaya bahasa Catch Me Up! menggunakan bahasa Indonesia sehari-hari yang dicampur dengan bahasa inggris.

Terdapat enam proses alur kerja, planning content (perencanaan konten), penentuan konten, riset berita (pencarian data-data yang dibutuhkan),pembuatan konten berita, proof reading (verifikasi oleh CEO dan editor). Tahapan pembuatan konten merupakan tahapan yang sangat penting karena disanalah strategi redaksi Catch Me Up! diterapkan kedalam setiap newsletter-nya.

\section{Daftar Pustaka}

Adek, Ferizal, dkk. 2017. Inovasi Media Online Dalam Menghadapi Persaingan Media Massa di Kota Bengkulu. Jurnal Professional FIS Unived. 4(2):72-81.

Al-Din, Ihya Ulum dan Wibawa, G.A. 2021. Strategi Media Digital Katadata Hadapi Pelemahan Ekonomi Karena Covid-19. Ekspresi dan Persepsi: Jurnal IImu Komunikasi. 4(1):4957.

Abidin, Yusuf Zainal. 2015. Manajemen Komunikasi: filosofi, konsep dan aplikasi. Bandung: Pustaka Setia.

Benazir, Dyas M. 2015. Kebijakan redaksional situs berita detikcom pada jejaring sosial twitter. UIN Syarif Hidayatullah Jakarta. Skripsi.

Cangara, Hafied. 2008. Pengantar IImu Komunikasi . Jakarta : Grafindo

Catch Me Up!. 2019. Tentang Kami. (Online) https://catchmeup.id/tentang-kami/. Diakses pada 16 Oktober 2020.

Fadylah, Istyas. 2010. Efektivitas Media Pembelajaran Mailing List Dalam Meningkatkan Hasil Belajar Siswa Kelas VII Pada Bidang Studi Pendidikan Agama Islam di SMP Islam Al-Azhar Kelapa Gading Surabaya. Uin Sunan Ampel 
Surabaya. (Online). http://digilib.uinsby. ac.id/8382/. Diakses pada 15 Oktober 2020.

Kriyantoro, Rachmat. 2014. Teknis Praktis Riset Komunikasi. Jakarta: Kencana Prena Media Group

KS, Usman. 2009. Ekonomi Media: Pengantar Konsep dan Aplikasi. Bogor: Ghalia Indonesia.

Manulang. 1996. Dasar-dasar Manajemen. Jakarta: Ghalia Indonesia.

Morgan, Roy. 2018. detikcom, KOMPAS.com \& LIPUTAN6 are Indonesia's-leading_news' websites (online). http://www.roymorgan .com/findings/7622-top-10-indonesiannews-websites-march-2018-2018061 72227. Diakses pada 15 Oktober 2020.

Nilasari, Senja. 2014. Manajemen Strategi itu Gampang. Jakarta: Dunia Cerdas

Okezone.com. 2016. 96\% Masyarakat Indonesia Konsumsi Berita Online (Online). https://economy.okezone.com/read/201 6/03/16/320/1337230/96-masyarakatindonesia-konsumsi-berita-online. Diakses pada 1 Oktober 2020.

Pattia, Ghea dan Radjagukguk, Djujur L. 2020. Strategi Manajemen Redaksi Radar Depok.com Dalam Menghadapi Persaingan di Era Digitalisasi. Jurnal Pupolis 5(9): 1449-1456.

Putri Pramesti, L., Alit Suryawati, I., \& Purnawan, N. 2019. Manajemen Media Massa Nusa Bali Pasca Kebijakan Konvergensi. E-Jurnal Medium, 1(1).

Prasetyo, Yosep A. 2018. Praktik Abal-Abal Versus Perlindungan Pers. Jurnal Dewan Pers.
18:12-23.

Rahma, Ellyta. 2020. Intip Suksesnya Catch Me Up! Manfaatkan Subscription Mode Untuk Konten Berita (Online). https://www. marketeers.com/intip-suksesnya-catchme-up-manfaatkan-subscription-modeuntuk-konten-berita/. Diakses pada 1 oktober 2020.

Siregar, Ashadi, 2006. Etika Komunikasi. Yogyakarta:Pustaka Book Publisher.

Warnosumarto, Subagio M. 2020. Jurnalisme Investigasi. Yogyakarta: Pustaka Baru Press.

Wibowo. 2017. Manajemen Kinerja. Edisi Kelima. Depok: PT. Raja Grafindo Persada. 


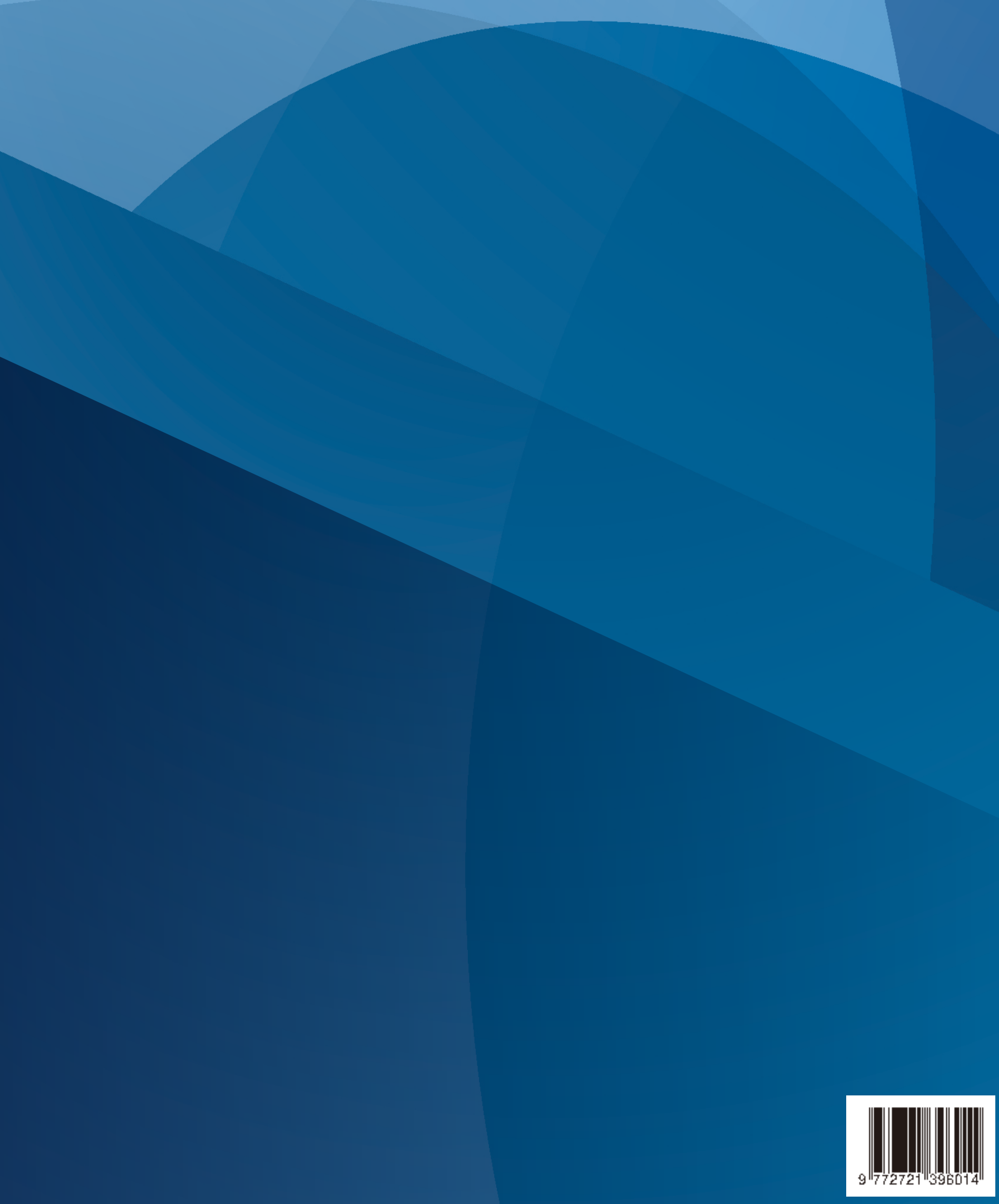

